\begin{tabular}{c}
\hline $\begin{array}{c}\text { International Journal of Current Research } \\
\text { and Academic Review } \\
\text { P }\end{array}$ \\
ISSN: 2347-3215 (Online) Volume 6 Number 12 (December-2018) \\
Journal homepage: http://www.ijcrar.com
\end{tabular}

doi: https://doi.org/10.20546/ijcrar.2018.612.004

\title{
Effectiveness of Teaching Intervention on Knowledge Regarding Modifiable Risk Factors on Care Givers of Patients with Coronary Artery Disease
}

\author{
Maneesha Scaria $^{1}$, Sany Alex ${ }^{1}$, Sneha Shaji ${ }^{1}$, C.V. Sheeja ${ }^{2^{*}}$ and T.M. Assuma Beevi ${ }^{3}$ \\ ${ }^{1}$ MIMS College of Nursing, Puthukode, India \\ ${ }^{2}$ Department of Medical Surgical Nursing MIMS College of Nursing, Puthukode, India \\ ${ }^{3}$ MIMS College of Nursing, MIMS Academy, Puthukode, India \\ *Corresponding author
}

\section{Abstract}

Coronary Artery supplies oxygenated blood to myocardium. Coronary Artery Disease occurs due to reduced supply of oxygenated blood to myocardial cells. Modifiable and non-modifiable risk factors are predisposing causes for Coronary Artery Disease. Each individual are responsible for their own health. Caregivers of patients are provided education about modifiable risk factors and if they are aware about preventive measures, they can reduce recurrence of these risk factors for patients. Thus reduces the morbidity of Coronary Artery Disease. This study has been undertaken in an attempt to provide information to caregivers for preventing modifiable risk factors of Coronary Artery Disease. Objectives of the study are: Evaluate the effectiveness of teaching intervention on care givers of patients regarding modifiable risk factors of CAD; Find the association between knowledge and selected demographic variables of care givers of patients with CAD. A quantitative approach with pre experimental one group pre-test - post-test design was used to evaluate teaching intervention. Non- Probability method through purposive sampling technique and Knowledge Questionnaire regarding Modifiable risk factors of CAD was used to collect data from caregivers of patient with CAD at Aster MIMS Hospital at Kozhikode. The findings of the study showed that in pre-test, majority of caregivers $(13.3 \%)$ had adequate knowledge, (80\%) had moderately adequate knowledge regarding modifiable risk factors of $\mathrm{CAD}$, and $(6.6 \%)$ had inadequate knowledge regarding modifiable risk factors of CAD. After intervention in the post-test results showed that majority of caregivers have adequate knowledge (83.3\%) and (16.6) have moderately adequate knowledge regarding modifiable risk factors of CAD. Incidence of Coronary Artery Disease can be reduced if individuals are able to modify their habits and make positive changes in lifestyle. By providing teaching intervention to caregivers of patient will help to adopt acceptable changes in day to day activities of life. Results of this present study demonstrate that teaching intervention can improve knowledge of caregivers regarding modifiable risk factors of Coronary Artery Disease. Implications for Nursing: Findings suggest that Staff Nurses should make efforts that are needed to improve the knowledge of caregivers of patient with CAD and decrease the morbidity of disease.
\end{abstract}

\section{Article Info}

Accepted: 18 November 2018

Available Online: 20 December 2018

Keywords

CAD-Coronary Artery Disease. 


\section{Introduction}

Coronary artery disease (CAD) is the major leading cause of death not only in high-income countries but also increasing in developing countries. ${ }^{1}$ Coronary artery disease is a condition in which the blood supply to cardiac muscle is partially or completely blocked. The atherosclerotic substances create blockage or narrow the vessels in a way that reduce blood flow to myocardium and the area become ischemic or injured. Several things increases the risk of coronary artery disease. The risk factors are classified as modifiable and non-modifiable risk factors. Most common modifiable risk factors are Hypertension, Diabetic Mellitus, hyperlipidemia, physical inactivity, stressful state, tobacco use and obesity.

Knowledge is an important pre-requisite for implementing both primary as well as secondary preventive strategy for CAD. In developed world the occurrence of CAD is increased. It is mainly seen in people with poor literacy rate and lack of awareness of disease symptoms. This is reflected in the rising rate of hospital admission and mortality rate. Prevention of CAD is the most effective way of combating CAD epidemic in resource poor nation ${ }^{2}$.

Estimating the level of knowledge of the population as large and those suffering from CAD can help to guide public health program especially those directed towards reducing modifiable risk factors of CAD. Increase in the risk of developing cardiovascular disorders in developing countries has been marked due to economic transition, urbanization, industrialization and globalization which bring about changes in lifestyle. ${ }^{3}$ The major causes of death are associated with modifiable risk factors particularly excessive alcohol and tobacco use, physical inactivity, high blood pressure, unhealthy diet, high lipids and diabetic mellitus ${ }^{4,5,6}$

It is the responsibility of Health care system to give primary and secondary preventive measures to reduce the occurrence of coronary artery diseases. Patients with $\mathrm{CAD}$ is increasing economic burden for the society and its sequelae are high for the Nation as the indirect cost is increasing due to disability, loss of work and mortality. In the developing world, cardiovascular disease tends to affect people at a younger age and thus could negatively affect workforce and economic productivity. ${ }^{7}$ Dietary changes that influence other metabolic pathways can also be beneficial. ${ }^{8,9}$
Making changes in lifestyle in an individual is difficult because many of the habits have been developed from their childhood onwards. So some of these changes can be achieved along with their family. Including family for care of patient will help to achieve the goal of modifying changes in lifestyle. In order to achieve a Therapeutic lifestyle changes such as Exercising regularly, Quitting smoking, Losing weight, and Eating right by patient would require family support. This is possible through family education on modifiable risk factors of CAD.

\section{Hypothesis}

$\mathbf{H}_{1}$ : There will be statistically significant difference between pre-test and post-test knowledge of care givers of patients with CAD on modifiable risk factors at 0.05 significance level.

$\mathbf{H}_{2}$ : There will be statistically significant association between knowledge of care givers of patient with CAD and selected demographic variables at 0.05 significance level.

\section{Delimitations}

- The study is delimited to a sample size of 30 .

- Duration of data collection is 3 weeks

\section{Materials and Methods}

A quantitative approach with pre experimental one group pre-test - post-test design was used to evaluate teaching intervention. Non- Probability method through purposive sampling technique and Knowledge Questionnaire regarding Modifiable risk factors of CAD was used to collect data from 30 caregivers of patient with CAD at Aster MIMS Hospital at Kozhikode. Reliability of 30item Knowledge questionnaire correlation coefficient was found to be 0.76.After acquiring Institutional Review Board approvals from Aster MIMS Hospital, permission of the Department authorities were obtained prior to the data collection. Patient Information Sheet was provided to caregivers of patients. Written informed consent was obtained from individual participants. Basic information was collected by using socio demographic questionnaire and clinical profile containing 12 items. Knowledge regarding modifiable risk factors of CAD on care givers of patients with CAD were assessed by using knowledge questionnaire with 30 items in structured questionnaire and a teaching intervention was given to the study participant on the same day. Post-test was done after seven days by using the same questionnaire. The data was collected for a period from 05-04-18 to 01-05- 
18. The obtained data was analyzed using descriptive and inferential statistics.

\section{Results and Discussions}

The knowledge questionnaire of caregivers included from major components of modifiable risk factors. For the purpose of interpretation of the scores, have been categorized into Inadequate knowledge (0-10), Moderately adequate knowledge (11-20), and Adequate knowledge (21-30)

\section{Demographic characteristics of caregivers of patient with CAD}

Socio demographic data shows that $33.3 \%$ care givers belongs to age group of 56-65 Years, $63.3 \%$ caregivers are males, $50 \%$ caregivers are Hindus, $43.3 \%$ caregivers have primary education, $83.3 \%$ caregivers have income within the range of 20000-80000, 63.3\% caregivers were married at the age group of 21-25 years, $76.6 \%$ caregivers belongs to the category of BMI below 25, $83.3 \%$ caregivers belongs to nuclear family, $46.6 \%$ caregivers have family history of diabetes mellitus and $50 \%$ caregivers have a history of use of anti-hypertensive drug.

The findings of the study showed in Table 1 that during pre-test, majority of caregivers $(80 \%)$ had moderately adequate knowledge regarding modifiable risk factors of CAD, (13.3\%) had adequate knowledge and (6.6\%) had inadequate knowledge regarding modifiable risk factors of CAD. After intervention the post-test results showed that majority of caregivers have adequate knowledge (83.3\%) and (16.6) have moderately adequate knowledge regarding modifiable risk factors of CAD.

Figure 1 and Table 2 depicts the mean pre-test knowledge score is $16.7 \pm 14.2$ whereas of posttest is $22.56 \pm 12.36$ and the calculated paired t' value (14.35) was greater than the table value (2.05) at df 29 . Hence the null hypothesis stating that there is no significant relationship between knowledge and teaching program on modifiable risk factors of CAD' is rejected. Thus it can be interpreted that there is significant relationship between knowledge and teaching intervention on modifiable risk factors of CAD on caregivers of patients with CAD. After the teaching intervention knowledge of care givers have improved.

The table 3 shows the association between selected demographic variables and knowledge score of caregivers on modifiable risk factors of CAD. There is significant association found between demographic variable such as gender $(\chi 2=18.07, \mathrm{p}<0.05)$, education $(\chi 2=10.61, p<0.05)$, occupation $(\chi 2=14.64, p<0.05)$ and knowledge of caregivers. So null hypothesis is rejected.

Table.1 Pre-test and post-test knowledge score among caregivers of patient with CAD

\begin{tabular}{|l|c|c|c|c|c|}
\hline \multicolumn{1}{|c|}{ Level of Knowledge } & Range of & \multicolumn{2}{|c|}{ Pre-test } & \multicolumn{2}{|c|}{ Post-test } \\
\cline { 3 - 6 } & Score & $\begin{array}{c}\text { Frequency } \\
(\mathbf{f})\end{array}$ & $\begin{array}{c}\text { Percentage } \\
(\boldsymbol{\%})\end{array}$ & $\begin{array}{c}\text { Frequency } \\
(\mathbf{f})\end{array}$ & $\begin{array}{c}\text { Percentage } \\
(\%)\end{array}$ \\
\hline $\begin{array}{l}\text { Inadequate knowledge } \\
\text { Moderately adequate } \\
\text { knowledge }\end{array}$ & $0-10$ & 2 & 6.6 & 0 & 0 \\
Adequate knowledge & $11-20$ & 24 & 80 & 5 & 16.6 \\
\hline
\end{tabular}

Table.2 Mean, mean difference, standard deviation, and t value of pre-test and posttest score of care givers of patients with CAD

\begin{tabular}{llllllll}
\hline & Mean & SD & $\begin{array}{l}\text { Mean } \\
\text { difference }\end{array}$ & $\begin{array}{l}\text { Tablet' } \\
\text { value }\end{array}$ & df & $\begin{array}{l}\text { Calculated } \\
\text { t' value }\end{array}$ & p- value \\
\hline Pre-test & 16.7 & 14.2 & & & & & \\
& & & 5.86 & 2.05 & 29 & $14.35^{*}$ & 0.001 \\
Posttest & 22.56 & 12.36 & & & & & \\
\hline
\end{tabular}


Table.3 Association between selected demographic variables and knowledge score of caregivers on modifiable risk factors of $\mathrm{CAD}$

\begin{tabular}{|l|c|c|c|c|}
\hline Variable & Chi-square & df & Table value & p- value \\
\hline Gender & 18.07 & 2 & $5.99^{*}$ & 0.05 \\
\hline Education & 10.61 & 4 & $9.49^{*}$ & 0.05 \\
\hline Occupation & 14.74 & 6 & $12.59^{*}$ & 0.05 \\
\hline
\end{tabular}

*(Significant at level of 0.05)

Figure.1 Mean, mean difference, standard deviation, and t' value of pre-test and posttest score of caregivers of patients with CAD

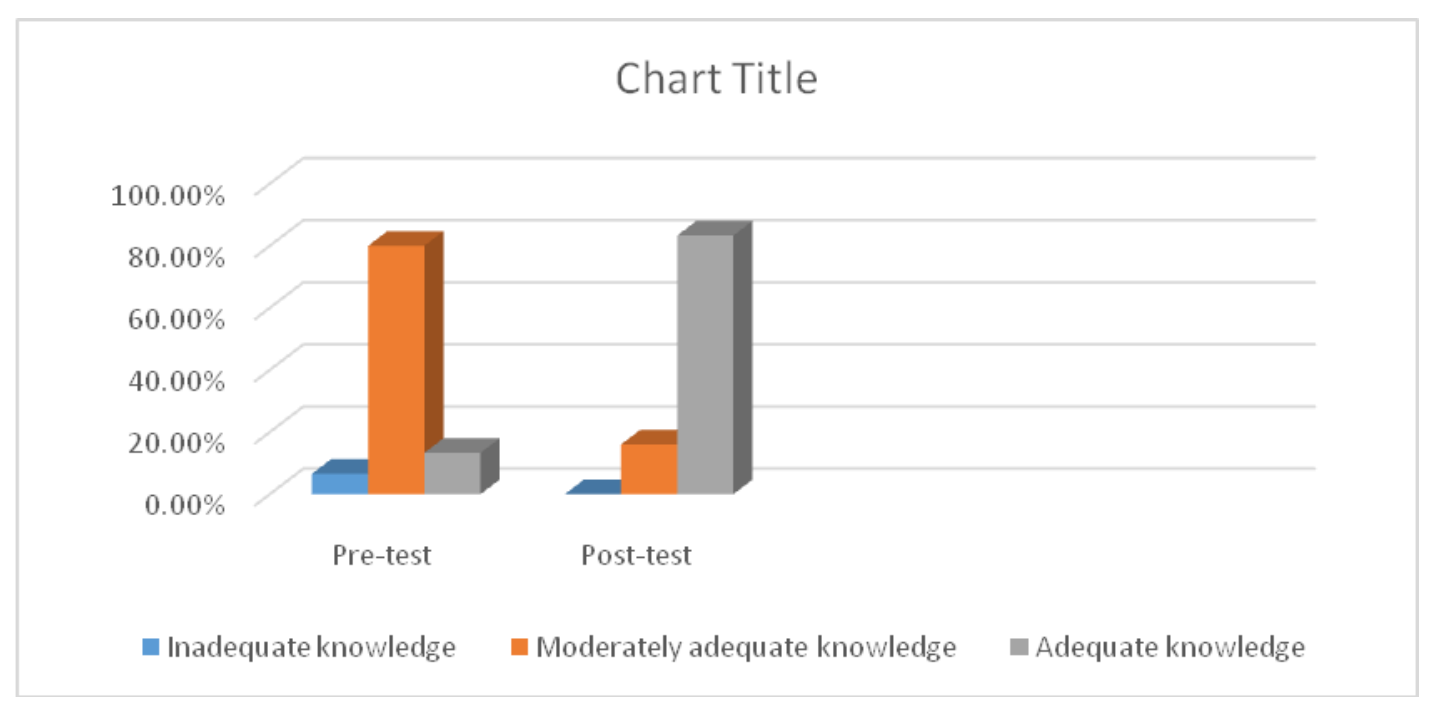

Results from the present study revealed that Education intervention improved the knowledge of caregivers regarding modifiable risk factors of CAD. The pre-test score of study revealed that majority of caregivers $(80 \%)$ had moderately adequate knowledge regarding modifiable risk factors of CAD, (13.3\%) had adequate knowledge and (6.6\%) had inadequate knowledge regarding modifiable risk factors of CAD. After intervention the post-test results showed that majority of caregivers have adequate knowledge (83.3\%) and (16.6) have moderately adequate knowledge regarding modifiable risk factors of CAD.

A similar study was conducted to assess the effectiveness of structured teaching program on knowledge regarding prevention on CAD among adults in Kale village. 30 caregivers were selected. The pre-test study revealed that majority of adult $(60 \%)$ had average knowledge, $(15 \%)$ had good knowledge and (25\%) had poor knowledge regarding prevention of CAD. After intervention the post-test knowledge showed that majority of adult have average knowledge (66.67\%), (23.33\%) had good knowledge and (10\%) had poor knowledge regarding prevention of CAD. ${ }^{10}$

Gender is considered as one of non-modifiable risk factor for CAD. Gender, Education status and occupation have association with knowledge on modifiable risk factors of $\mathrm{CAD}$, as the education level of caregivers' increases, they are able to acquire more knowledge regarding modifiable risk factors. Occupation also have association either positive or negative ways. Stress on 
job may increase predisposition for Coronary artery disease.

\section{Implications}

A nurse working in the community will be able to teach the caregivers about modifiable risk factors of CAD. Thus the nurse can act as an educator and it helps to prevent further complications by modifying the risk factors of CAD. Nurses are encouraged to conduct more research relating to this topic to increase evidence based practice by the nurses.

In conclusion, Life style diseases are leading cause for CAD. Coronary artery disease can be prevented by making life style changes in day to day life. When the individuals are able to modify the risk factors according to their need requirements, the target of disease prevention can be achieved. Making changes in dietary habits and increasing physical activity can modify the risk factor. Thus individuals can improvetheir own health.The morbidity and mortality caused by these factors can be reduced. Premodial and primary preventionalso will be achieved by Nurses.

\section{References}

1. GBD Mortality Causes of Death Collaborators, Global, regional, and national age-sex specific all-cause and cause-specific mortality for 240 causes of death, 1990-2013: a systematic analysis for the Global Burden of Disease Study 2013. Lancet. 2015;385:117-71

2. Black M J. (2009). Luck Mann and Sorenson's "Medical Surgical Nursing Psycho physiologic Approach Philadelphia: W B Saunders Company (1627-1645).

3. BeLue R, Okoror TA, Iwelunmor J, Taylor KD, Degboe AN, et al., (2009) an overview of cardiovascular risk factor burden in sub-Saharan African countries: a socio-cultural perspective. Global Health 5: 10.

4. Rodriguez BL, Fujimoto WY, Mayer-Davis EJ, Imperatore G, Williams DE (2006) Prevalence of cardiovascular disease risk factors in U.S. children and adolescents with diabetes. Diabetes Care 29: 1891-1896.

5. Odunaiya NA, Ayodele AO, Oguntibeju OO (2010) Physical activity levels of senior secondary school students in Ibadan, western Nigeria. West Indian Med J 59: 529-534.

6. Tibazarwa K, Ntyintyane L, Sliwa K, Gerntholtz T, Carrington M (2009) A time bomb of cardiovascular risk factors in South Africa: results from the Heart of Soweto Study "Heart Awareness Days". Int J Cardiol 132: 233-239.

7. Leeder SR, Raymond S, Greenberg H. A Race Against Time: The Challenge of Cardiovascular Disease in Developing Economies Sidney, Australia: Earth Institute at Columbia University; 2004. http://www.earth.columbia. edu/news/2004/images/raceagainsttime

8. Burr ML, Fehily AM, Gilbert JF, et al., Effects of changes in fat, fish and fibre intakes on death and myocardial re-infarction: Diet and Reinfarction Trial (DART). Lancet. 1989; 2: 757761.PubMedGoogle Scholar

9. De Logeril M, Salen P, Martin JL, et al., Mediterranean diet, traditional risk factors and the rate of cardiovascular complications after myocardial infarction: final report of the Lyon Diet Heart Study. Circulation. 1999; 99: 779785

10. Ujwala R, Pradnya SK, Avinash HS, International Journal of Science and Research. Available in http://www.ijsr.net/archive/v4i8/ SUB157164.pdf

\section{How to cite this article:}

Maneesha Scaria, Sany Alex, Sneha Shaji, C.V. Sheeja and Assuma Beevi, T.M. 2018. Effectiveness of Teaching Intervention on Knowledge Regarding Modifiable Risk Factors on Care Givers of Patients with Coronary Artery Disease. Int.J.Curr.Res.Aca.Rev. 6(12), 37-41. doi: https://doi.org/10.20546/ijcrar.2018.612.004 